\title{
On Ecosystem Doctoring
}

\section{Healing as an occasion for learning}

One of Aldo Leopold's most widely quoted lines is one in which he draws an analogy between nature, or plant and animal communities, and a machine.

"If the land mechanism as a whole is good," he wrote in Round River, "then every part is good, whether we understand it or not. If the biota, in the course of eons, has built something we like but do not understand, then who but a fool would discard seemingly useless parts? To keep every $\operatorname{cog}$ and wheel is the first precaution of intelligent tinkering."

This neat, Newtonian analogy is often used as an argument for conservation of species and communities, and it has always suggested to us something about the nature and value of attempts to restore ecosystems. In particular, it suggested to us that, in addition to its obvious practical value (a fixed clock is better than a broken one), the business of putting ecosystems back together ought to have considerable heuristic value as well-that is, it ought to be a good way of testing ideas about the "land mechanism," of learning about it and how it works.

Clearly this is true for clocks. If I can assemble a clock or fix a broken one, it is pretty clear that I understand how it works.

The problem is that it really isn't true about ecosystems-or at least not quite so strictly true-simply because plants and animals are alive, and to a very considerable extent make their own way back into the pattern, often without any help at all. And this obviously qualifies the idea that reconstruction of a community proves that the restorationist understands it in detail in the way the clockmaker's or the chemist's ability to reassemble, repair, or synthesize proves he fully understands the working of a machine or the structure of a molecule.

Still we are intrigued by the idea of restoration as a way of learning about communities and ecosystems. And in ruminating on this, and reflecting on the shortcomings of the clock metaphor, we find ourselves turning to another, much older metaphor - the idea of earth as an organism, and communities and ecosystems as interacting parts of an organic whole comparable to the organs or tissues of an organism.

Of course this is an idea that is deeply rooted in ancient systems of thought and belief about the earth and man's relationship to it. It is an idea and a metaphor Leopold used, and in fact it recurs in his writings together with the machine metaphor.

One of his clearest statements of this analogy is in an unpublished essay cited by Roderick Nash in his Wilderness and the American Mind. Reflecting on a vacation trip into the Sierra Madre in the early 1930s, Leopold wrote, "It was here that I first clearly realized that land is an organism, that all my life I had seen only sick land, whereas here was a biota still in perfect aboriginal health."

Recently Zoologists David Rapport and Henry Regier at the University of Toronto have picked up this theme, elaborating the analogy it suggests between ecology and medicine, and discussing the medical concepts of diagnosis, prognosis, and treatment as they may apply to ecosystems (in: Stress Effects on Natural Ecosystems, G.W. Barrett and R. Rosenberg, editors, Wiley, 1981).

This seems to us a better metaphor for the land than the mechanical one. And one of the things that intrigues us most is the way it helps refine our thinking about the heuristic value of the restoration and management effort. It may be that the fact that we can nurse, say, a prairie back to health doesn't prove we fully understand how it works - any more than the ability to set a broken bone proves a physician knows all there is to know about the structure and physiology of bone. Nevertheless it is certainly true that undertaking such tasks places the healer in an excellent position to raise new questions, and in some cases perhaps even to answer them.

That this is true at the organism level is clear from the contributions physicians and medical researchers have made to fundamental understanding of anatomy, physiology, heredity, embryology, and the immune system.

And certainly management efforts have already contributed to basic ecological thinking. Our favorite example, because it was done here at Wisconsin, is the classic research on prairie fire that was undertaken when the early attempts to restore prairie proved disappointing (R\&MN I:3, p. 7). This contributed not only to the rediscovery of an ancient environmental management technology, but also to basic insights into the ecology of prairies.

Of course it remains to be seen just how powerful or useful this approach is. It has been said, and it is certainly true, that the use of fire as a tool in prairie management was so obvious that it would have been developed anyway, whether prairie restoration had been attempted or not. Moreover, in other cases, there may be much easier ways to test hypotheses. Nevertheless, we think this is something worth considering as we think about restoration and management and its implications both for science and for the environment.

Among other things, it suggests to us that research on restoration and management ought to be undertaken in circumstances rather like those in a research hospitalthey ought to involve both theoreticians and practitioners working together, as Mike Gilpin points out in his thoughtful piece on the relationship between his own highly theoretical laboratory research and community restoration in the field (page 11).

Professor Gilpin also raises another point directly related to the medical analogy when he notes that restoration projects are almost invariably too big and too costly to set up specifically as experiments, at least in the more basic sense. Moreover, of course, most sites are too valuable, both ecologically and in many cases economically, to tinker with them on a large scale.

In short, the situation is strikingly like what we find in human medicine where we cannot, for ethical reasons, experiment deliberately, but where experiments are thrust upon us, and it is up to us to make the most of them when we can. 
It is with this in mind that Gilpin calls for managers to become more "hypothesis conscious" in their dealings with the communities in their charge. He also calls for the pooling of data - precisely as is done by physicians to help make up for the inadequacies presented by data gathered in the course of efforts undertaken for other reasons.

Both of these seem to us to be intriguing suggestions, and we hope to hear more of them in the future.

\section{Summing Up Volume I}

When we sent out the first issue of Restoration and Management Notes two years ago, we had no idea what would come of it. We thought there was a need for better communication in this area; we thought we had put together a first issue that represented fairly well what we could do to encourage that communication; and we had compiled a good list of prospective readers. That first, complimentary issue was mailed to some 2400 persons all over the country. It made an impressive pile in the back of the arboretum van. But we had no idea how many of those receiving it would read it, or how many, having read it, would want to see another copy.

Now as we mail off this fourth and final issue of Volume I, we are happy to report that a great many of those persons did want to see more. The response to R\&MN has exceeded our expectations severalfold; we now have more than 1,400 subscribers - an impressive number for a young publication without a ready-made audience, and with limited resources for promotion.

The point is that R\&MN is working, and it is working because our readers are enthusiastic about it. They read it - some of them apparently with a fine-toothed comb. They write us about it, and they tell others about it. And that's great because our subscribers are also contributors. The more of them we have the more valuable Notes will be, the more it will contain, the more persons it will put you in touch with; and, not insignificantly, the more economically we can produce it.

Last winter we included a reader reply card in the third issue, hoping to get some advice on a few questions that keep coming up. We think some of the answers are worth passing on.

In general, readers who responded seemed to like what we are doing. Most of them indicated they read more than half of each issue, and many wrote they read 90 or 100 percent. In the same vein, there was little interest in cutting anything out, though there were a few comments on notes from the southeast or the west-areas not included in our region, defined, tentatively, along ecologi$\mathrm{cal}$ lines to include the forests, prairies and wetlands of the eastern United States. So far we have stuck to this, but only loosely, and we have accepted contributions from farther afield if we felt they would interest our midwestern and eastern readers. There has been real interest in having R\&MN expand to include the entire United States, or all of North America. In particular we have heard from persons in Florida and California, both areas where restoration and management seem to be especially vigorous enterprises. And in a review in the winter issue of CoEvolution Quarterly, Peter Warshall described R\&MN as ". . . a great success," that "... should be copied in every other bioregion of the planet." Obviously this is something we will be considering, and, as usual, opinions are welcome.

As to subjects, our respondents like what's there and would like to see more of the same. They call for more of everything - from the nitty-gritty of propagation and pest control to history and philosophy. Readers clearly like the style and format-especially the preponderance of short notes with names and addresses. Bonnie Harper of Northfield, Minnesota was kind enough to report that "I read with interest more pages of R\&MN than the rest of my professional periodicals combined." Still the inclusion of a few longer articles in each issue has generally been welcome, with a majority of readers reporting they'd like to see more of them.

As to the metric system - that also fared surprisingly well. Forty percent of our respondents are happy with the metric system alone. Another third would like to see both metric and English units used together. Only a few urged English only. For the moment we are following a course somewhere midway-metric system, with occasional exceptions as appropriate, and with a conversion table inside the front cover - a suggestion made by several readers.

We also picked up a lot of ideas from the reply cards, some of which we'll be following up on. One, from Mark Heitlinger at The Nature Conservancy, was for the comprehensive index, which we have included at the back of this issue.

Keep in touch! 